\title{
Spatial variation modeling of groundwater electrical conductivity using geostatistics and GIS
}

\author{
Javad Seyedmohammadi $^{1} \cdot$ Leila Esmaeelnejad $^{2} \cdot$ Mahmood Shabanpour $^{3}$
}

Received: 27 August 2016/Accepted: 27 September 2016/Published online: 3 October 2016

(C) Springer International Publishing Switzerland 2016

\begin{abstract}
Optimized management of water resources, conservation and their quality increase is needful with data existence in basis of situation, amount and distribution of water chemical factors for example; electrical conductivity (EC) in determined geographical region. Accuracy of interpolation appropriate methods and variation map preparation of groundwater quality variables is independent to region conditions and existence of enough data. That is true selection of interpolation methods is basic and important step in management of groundwater resources. EC is one of the important indicators for groundwater quality evaluation. The objective of this research was to determine the most suitable interpolation method and their accuracy for analysis and checking spatial variation of groundwater EC amount in central regions of Guilan province, northern Iran. This investigation evaluated the inverse distance weighting (IDW), global polynomial interpolation (GPI), local polynomial interpolation (LPI), radial basis function (RBF) and ordinary kriging (OK) methods for estimation of groundwater EC in paddy fields. In IDW method, for variable estimation used power value 1-5 that power value equal 1 was exact. Gaussian model was the best one fitted on empirical semivariogram of variable data in $\mathrm{OK}$ method. Standard statistical
\end{abstract}

Javad Seyedmohammadi

seyedmohammadi.javad@gmail.com

1 Department of Soil Science, Faculty of Agriculture, University of Tabriz, Tabriz, Iran

2 Department of Soil Science, Faculty of Agricultural Engineering and Technology, College of Agriculture and Natural Resources, University of Tehran, Karaj, Iran

3 Department of Soil Science, Faculty of Agriculture, University of Guilan, Rasht, Iran performance evaluation criteria include root mean square error (RMSE), correlation coefficient (R) and mean absolute error (MAE) were used to control the accuracy of the prediction capability of the developed methods. Results showed that the best estimator was OK method which was the most exact with regard to other methods for estimation groundwater electrical conductivity.

Keywords EC · Geostatistics · GPI · IDW · LPI · Ordinary kriging $\cdot \mathrm{RBF}$

$\begin{array}{ll}\text { Abbreviations } \\ \text { CV } & \text { Coefficient of variation } \\ \text { EC } & \text { Electrical conductivity } \\ \text { ER } & \text { Effective range } \\ \text { IDW } & \text { Inverse distance weighting } \\ \text { GPI } & \text { Global polynomial interpolation } \\ \text { LPI } & \text { Local polynomial interpolation } \\ \text { MAE } & \text { Mean absolute error } \\ \text { OK } & \text { Ordinary kriging } \\ \text { R } & \text { Correlation coefficient } \\ \text { RBF } & \text { Radial basis function } \\ \text { RMSE } & \text { Root mean square error } \\ \text { RSS } & \text { Residual sums of squares } \\ \text { SD } & \text { Standard deviation }\end{array}$

\section{Introduction}

Groundwater resource is commonly the most important water resource in semi-arid and arid areas that are often subject to water shortage. It plays a fundamental role in supplying clean and safe water to competing uses for domestic, industrial and agricultural sectors, and increasing attentions are also paid to its significance for ecological 
integrity. However, groundwater aquifer systems always feature complexity, high nonlinearity, being multi-scale and random as a result of the frequent interactions between surface water and groundwater as well as acute human disturbance (Nourani et al. 2015; Han et al. 2016). Thus, effective modeling techniques would be required for providing efficient ground water management strategies.

Sustainable groundwater quality is important for drinking, irrigation and domestic purposes. Groundwater resources are importance water resources for agricultural uses and potation in Iran and many other countries that have climate similarly to Iran climate. Beside pollution low danger of these resources with regard to other resources is caused in regions that surface water resources is enough, in spite of groundwater resources are used for agricultural uses. Waters pollution topic is explanation in developed and development per condition countries. For example in many cities of Iran, because potation water derived from groundwater resources therefore should be noticed that these resources not polluted with nitrate ion and other toxic elements. These toxic agents can be produced from fertilizers, pesticides and sewage. Therefore during recent years, increasing pollution and losing of water resources have changed exploitation policy of water and soil resources.

Prior to the design of groundwater quality monitoring networks, it is essential to investigate the spatial structure of the groundwater quality variables to be monitored such as electrical conductivity. Generally, the objective of monitoring, introduces these variables. For example, greater monitoring effort is required for groundwater to be used for domestic (municipal) purposes than for agricultural use. The aim of characterizing the spatial structure of the variables is not only to assess their monitoring, which is needed to assess the cost of monitoring, but also to give a clear picture about their spatial variability or structure. The spatial structure of the groundwater quality variables can produce, for example, contour maps of the variable means. These maps can be used for predicting and signifying pollution areas. Accordingly, protection measures, management and planning decisions can be made to minimize the deterioration in the polluted areas (Zehtabian et al. 2013; Shrestha et al. 2016).

Geostatistical methods were developed to create mathematical models of spatial correlation structures with a variogram as the quantitative measure of spatial correlation. The variogram is commonly used in geostatistics and the interpolation technique, known as kriging, provides the best, unbiased, linear estimate of a regionalized variable in a no sampled location, where best is defined in a leastsquares sense. The emphasis is set on local accuracy, i.e. closeness of the estimate to the actual, but unknown, value without any regard for the global statistical properties of the estimates. The kriging estimation variances are independent of the value being estimated and are related only to the spatial arrangement of the sample data and to the model variogram. One development of geostatistics, that has become more popular in the last decade, is the stochastic simulation which represents an alternative modeling technique, particularly suited to applications where global statistics are more important than local accuracy (Webster and Oliver 2008). Application of geostatistics techniques in hydrological sciences is a useful approach to avoid some errors and increase of calculation accuracy as well. In classic statistic samples taken from a population are lack of spatial properties. Therefore the calculated values of a parameter in a homogeny sample do not include any information of the same parameter in another sample with a defined distance. Geostatistics consider the value as well as location of the sample. Then it is possible to analyze value and location of the samples together. To achieve this purpose it is necessary to relate spatial properties (distance, direction) of different samples using mathematical formula called spatial structure (Babakhani et al. 2016).

Natural resources and environmental concerns, including groundwater, have benefited greatly from the use of Geographic Information System. One can use GIS to integrate spatial data with other information. GIS is used for analyzing and presenting the spatial information, which facilitates the environmental protection, and resource planning. GIS also help in finding the close relationship between water quality and various natural or anthropogenic activities (Dhanasekarapandian et al. 2016). ArcGIS geostatistical analyst effectively bridges the gap between geostatistics and GIS analysis (Kumar et al. 2007; Nas 2009). Geostatistical analysis has been useful to determine water variables in space and time. Many studies have successfully used interpolation techniques with and without the use of the ArcGIS Geostatistical tool (Nas 2009).

Obviously geostatistical methods use various variables and then produce different results. In many causes a method which is selected to reach the prediction process but it is vital to find out the most appropriate interpolation technique for precipitation prediction. The accuracy of interpolation methods for spatially predicting soil and water properties has been analyzed in several studies. Safari (2002) used kriging method to estimate spatial prediction of Groundwater in Chamchamal plain in west of Iran. Results showed that suitable method of geostatistics to estimate one variable depends on variables type and regional factors which influence this and any selected method for given region cannot be generalized to others. Nazarizadeh et al. (2005), used geostatistics method to study spatial variability of Groundwater quality in Balarood plain. Their results showed spherical model is 
the best model for fitting on experimental variogram of EC variable. Ahmed (2002) used kriging method to estimate total dissolution solid in Groundwater and demonstrated accuracy of this method to prediction of total dissolution solid.

Kriging techniques are employed to assess the spatial dependencies of the water quality variables such as total dissolution solid (Babakhani et al. 2016), groundwater level (Ahmed 2002) and groundwater quality variables such as $\mathrm{NO}_{3}$ and $\mathrm{Cl}^{-}$(Nas 2009). Sainato et al. (2003) introduced kriging method as most acceptable and strongest tool to interpolate data for preparation of contour maps of groundwater. Zehtabian et al. (2013) used two techniques including kriging and Weighted Moving Average (WMA) for presenting spatial variation of groundwater properties such as EC. Finally comparison of the results using statistical techniques showed that kriging technique performed better than WMA technique. Ordinary kriging method was used by Nas (2009) in konya of Turky, to produce the spatial pattern of groundwater quality over the study area. The result of kriging interpolation showed that higher electrical conductivity is clearly situated in the northeast of the study area. Mehrjardi et al. (2008) used IDW and kriging methods for predicting spatial distribution of some Groundwater characteristics such as: EC. Their results showed that for interpolation of Groundwater EC, kriging method is superior to IDW method. Baram et al. (2014) demonstrated that analyzing vadose zone and groundwater data by spatial statistical analysis methods can significantly contribute to the understanding of the relations between groundwater contaminating sources, and to assessing appropriate remediation steps. Bodrud-Doza et al. (2016) used ordinary kriging interpolation method for taking initial decision of spatial distribution of groundwaterquality parameters. Their results represent that the ordinary kriging technique is able to predict spatial variability more accurately for the study area with suitable semivariagram model. They reported that outcomes of the study will provide insights for decision makers taking proper measures for groundwater quality management in central Bangladesh.

Groundwater monitoring can provide fundamental information to sustainable water resource management. The goals of groundwater monitoring can be ambient resource condition, compliance, risk detection, and research monitoring, or a combination of these. Land and water management practices should be developed according to results of continuous monitoring of water table depth and groundwater qualities. In irrigated areas, monitoring wells commonly used to evaluate spatial and temporal changes in water table level and groundwater quality (Kurunc et al. 2016).
Groundwater quality variables mapping is an important tool for groundwater management and risk assessment. As nearly years, dominant water of agricultural fields in Guilan province was supplied by groundwater and in recent decades, exploitation of water and soil resources has been changed generally by excavation of many wells, deep and mid-deep. Therefore, sustainable management of water and soil resources requires being informed from changes of Groundwater quality. The present study carried out with objective to evaluate accuracy of different interpolation methods include OK, IDW, RBF, LPI and GPI for prediction of groundwater electrical conductivity parameter in central areas of Guilan province in northern Iran.

\section{Materials and methods}

\section{Study area}

The study area is located between $49^{\circ}, 31^{\prime}-49^{\circ}, 45^{\prime} \mathrm{E}$ longitude and $37^{\circ}, 7^{\prime}-37^{\circ}, 27^{\prime} \mathrm{N}$ latitude in northern Iran bordering to Caspian Sea in Guilan province. The climate of the region is humid with the mean annual precipitation of $1293.6 \mathrm{~mm}$. The mean annual temperature of the region and humidity are $15.8{ }^{\circ} \mathrm{C}$ and $75 \%$, respectively. The annual evapotranspiration is $850 \mathrm{~mm}$. The soil moisture and temperature regimes of the region by means of IRAN regimes maps are Udic or Aquic and Thermic, respectively. The major geological formations are composed of thick sedimentary and metamorphic rocks of Tertiary and Quaternary periods. The coastal plain lying between Alborz mountain ranges and Caspian Sea is composed of marine, river and aeolian deposits of varying thicknesses. The physiographical units of the region from south to north direction are upper plateaus, river alluvial plains, river bank, low lands and coastal lands, respectively. This studying area is 40000 ha. 341 samples were collected from groundwater randomly for determining electrical conductivity. Figure 1 shows the study area and distribution of sampling points.

\section{Interpolation methods}

\section{Inverse distance weighting (IDW)}

The IDW is one of the mostly applied and deterministic interpolation techniques in the field of soil science. IDW estimates were made based on nearby known locations. The weights assigned to the interpolating points are the inverse of its distance from the interpolation point. Consequently, the close points are made-up to have more weights (so, more impact) than distant points and vice versa. The known sample points are implicit to be self- 

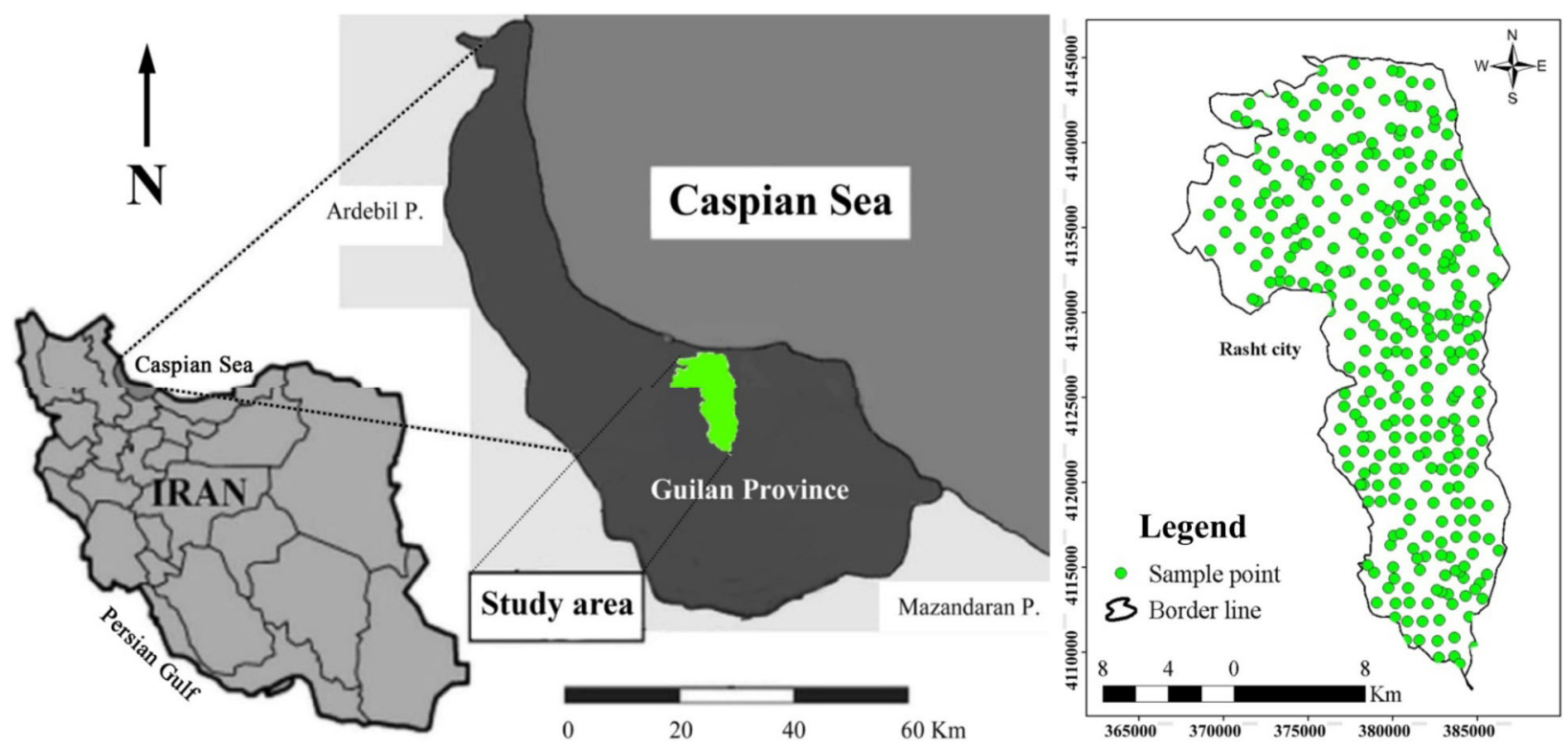

Fig. 1 Spatial distribution of sampling site and geographic location of studying area

governing from each other (Robinson and Metternicht 2006; Bhunia et al. 2016).

$\boldsymbol{Z}\left(\boldsymbol{x}_{0}\right)=\frac{\sum_{i=1}^{n} \frac{\boldsymbol{x}_{i}}{h_{i j}^{\beta}}}{\sum_{i=1}^{n} \frac{1}{h_{i j}^{\beta}}}$

where, $Z\left(x_{0}\right)$ is the interpolated value, $n$ representing the total number of sample data values, $x_{i}$ is the ith data value, $h_{i j}$ is the separation distance between interpolated value and the sample data value, and $\beta$ denotes the weighting power.

\section{Global polynomial interpolation (GPI)}

Global polynomial fits a polynomial formula to the sample points. Conceptually, global polynomial positions a plane between the sample points. The unknown height is then determined from the value on the plane that corresponds to the prediction location. The plane may be above certain points and below others. The goal for global polynomial is to minimize errors. Global polynomial interpolation fits a smooth surface that is defined by a mathematical function (a polynomial) to the input sample points. The Global polynomial surface changes gradually and captures coarsescale pattern in the data. Conceptually, Global Polynomial interpolation is like taking a piece of paper and fitting it between the raised points (raised to the height of value) (Webster and Oliver 2008).

\section{Local polynomial interpolation (LPI)}

Local polynomial fits many smaller overlapping planes to the sample points, and then uses the center of each plane as the prediction for each location in the study area Local polynomial interpolation creates a surface from many different polynomial formulas, each is optimized for a specified neighborhood, the neighborhood shape, maximum and minimum number of points, and a sector configuration can be specified, the sample points in a neighborhood can be weighted by their distance from the prediction location (Hani and Abari 2011).

\section{Radial basis function (RBF)}

Radial basis function methods are a series of exact interpolation techniques; that is, the surface must go through each measured sample value. RBF methods are a form of artificial neural networks. RBFs are like a rubber membrane that is fitted to each of the measured data points, while minimizing the total curvature of the surface and exact method that means the surface must pass through each sampled point (Lin and Chen 2004; Bhunia et al. 2016).

\section{Ordinary kriging $(\mathrm{OK})$}

Kriging is one of the most popular and robust interpolation techniques among other techniques. It integrates both the spatial correlation and the dependence in the prediction of a known variable. Estimations of nearly all spatial interpolation methods can be represented as weighted averages of the sampled data (Bodrud-Doza et al. 2016). The presence of a spatial structure where observations close to each other are more alike than those that are far apart (spatial autocorrelation) is a prerequisite to the application of 
geostatistics. The experimental variogram measures the average degree of dissimilarity between no sampled values and a nearby data value, and thus can depict autocorrelation at various distances. The value of the experimental variogram for a separation distance of $h$ (referred to as the lag) is half the average squared difference between the value at $Z\left(x_{i}\right)$ and the value at $Z\left(x_{i}+h\right)$ (Eq. 2).

$\gamma(\boldsymbol{h})=\frac{1}{2 \boldsymbol{N}(\boldsymbol{h})} \sum_{i=1}^{N(\boldsymbol{h})}\left[\boldsymbol{Z}\left(\boldsymbol{x}_{i}\right)-\boldsymbol{Z}\left(\boldsymbol{x}_{i}+\boldsymbol{h}\right)\right]^{2}$

where: $N(h)$ is the number of data pairs within a given class of distance and direction. If the values at $Z\left(x_{i}\right)$ and $Z\left(x_{i}+h\right)$ are auto correlated the result of Eq. 2 will be small, relative to an uncorrelated pair of points (Wang and Shao 2013).

Variogram plots (experimental variograms) were acquired by calculating variogram at different lags. Gaussian model was selected in order to model experimental variogram and acquire information about the spatial structure as well as the input parameters for kriging estimation. The Gaussian model is defined as Eq. 3:

$\gamma(\boldsymbol{h})=\boldsymbol{C}_{0}+\boldsymbol{C}\left[1-\boldsymbol{e x p}\left(-\frac{\boldsymbol{h}^{2}}{\boldsymbol{a}^{2}}\right)\right]$

where: $C_{0}$ is the nugget variance $(h=0)$, which represents the experimental error and field variation within the minimum sampling spacing. Typically, the variogram increases with increasing lag distance to attain or approach a maximum value or sill $\left(C_{0}+C\right)$ almost equivalent to the population variance, i.e., priori variance. $C$ is the structural variance and $a$ is the spatial range across which the data exhibit spatial correlation. For Gaussian model, the practical range is defined as $\sqrt{ } 3 a$ (Dayani and Mohammadi 2010; Ducci et al. 2016).

From analysis of the experimental variogram, a suitable model (e.g. Gaussian, Spherical, and Exponential) is then fitted, usually by weighted least squares, and the parameters (e.g. range, nugget and sill) are then used in the kriging procedure. The ratio of nugget effect to sill can consider for evaluation of spatial structure of data. When this ratio is smaller than 0.25 the concerned parameter has a strong spatial steal structure, between $0.25-0.75$ spatial structure is middle, and when it is greater than 0.75 spatial structures is weak (Shi et al. 2007). The first step for using geostatistic methods is to study the existence of spatial structure between data by analysis variogram. The condition of this analysis is that data must be normal. One of the evaluation methods for nominate normality of data is usage of skewness coefficient. When skewness coefficient is lower than 0.5 there is no need to convert data, but if this coefficient is between 0.5 and 1 , and more than 1 for normalizing data square root and logarithm must be used, respectively (Robinson and Metternicht 2006). In order to know the data were normal, Kolmogorov-Smirnov test was used.

\section{Performance evaluation criteria}

Three different types of standard statistical performance evaluation criteria were used to control the accuracy of the prediction capacity of the models developed. These are root mean square error (RMSE), the correlation coefficient (R) and mean absolute error (MAE). Performance evaluation criteria used in the current study can be calculated using following equations:

$\boldsymbol{R M S E}=\sqrt{\frac{1}{n} \sum_{i=1}^{n}\left(\boldsymbol{y}_{i}-\hat{y}_{i}\right)^{2}}$

$\boldsymbol{R}=\sqrt{1-\left[\frac{\left(\sum_{i=1}^{n}\left(\boldsymbol{y}_{i}-\hat{\boldsymbol{y}}_{i}\right)^{2}\right)}{\left(\sum_{i=1}^{n}\left(\boldsymbol{y}_{i}-\bar{y}_{i}\right)^{2}\right)}\right]}$

$\operatorname{MAE}=\frac{1}{n} \sum_{i=1}^{n}\left|y_{i}-\hat{y}_{i}\right|$

where; $\boldsymbol{y}_{\boldsymbol{i}}$ denotes the measured value, $\hat{\boldsymbol{y}}_{\boldsymbol{i}}$ is the predicted value, $\bar{y}_{i}$ is the average of the measured value, and $\mathrm{n}$ is the total number of observations.

All statistical calculations were performed using Microsoft Excel and SPSS 24. Geostatistical analyses and generation of prediction maps of water EC were carried out with $\mathrm{GS}^{+}$9.0 (Gamma Design Software LLC., Plainwell, MI) and ArcGIS 10.3.1 (ESRI, Redlands, CA, USA) software.

\section{Results and discussion}

The use of current and traditional methods for investigation of changes of spatial structure of groundwater quality variables are expensive and time-consuming methods. On the other hand classic statistics cannot consider spatial changes of variables. Physical and chemical characteristics of water resources change in time and place, even spatial structure of water variables change in various geographic directions. Therefore in this research geostatistical methods are used to consider spatial structure and changes of groundwater electrical conductivity. Some statistical characteristics such as mean, standard deviation, minimum, maximum, coefficient of variation, skewness, and kurtosis are presented in Table 1 for the variable. In spite of data skewness more than 0.5 but data had not normal distribution. Therefore, square root transform was used to normalize data and its result is mentioned in Table 1 which 
Table 1 Statistics of data used in research

\begin{tabular}{lllllllr}
\hline Variable & Minimum & Maximum & Mean & SD & CV (\%) & Skewness & Kurtosis \\
\hline EC & 0.50 & 1.70 & 0.98 & 0.24 & 24 & 0.66 & 0.03 \\
EC $^{\text {a }}$ & 0.71 & 1.30 & 0.98 & 0.12 & 12 & 0.35 & -0.14 \\
\hline
\end{tabular}

$S D$ standard deviation, $C V$ coefficient of variation

a Square root transform of EC

Table 2 Properties of used model in kriging method

\begin{tabular}{lllllllll}
\hline Variable & Method & Model & $\mathrm{C}_{0}$ (Nugget effect) & $\mathrm{C}_{0}+\mathrm{C}($ Sill $)$ & $\mathrm{ER}(\mathrm{m})$ & $\mathrm{C} /\left(\mathrm{C}_{0}+\mathrm{C}\right)$ & $\mathrm{R}^{2}$ & $\mathrm{RSS}$ \\
\hline EC & Kriging & Gaussian & 0.003 & 0.0121 & 8313.84 & 0.752 & 0.97 & $5.6 \times 10^{-7}$ \\
\hline
\end{tabular}

$E R(\mathrm{~m})$ effective range according to meter, $R S S$ residual sums of squares

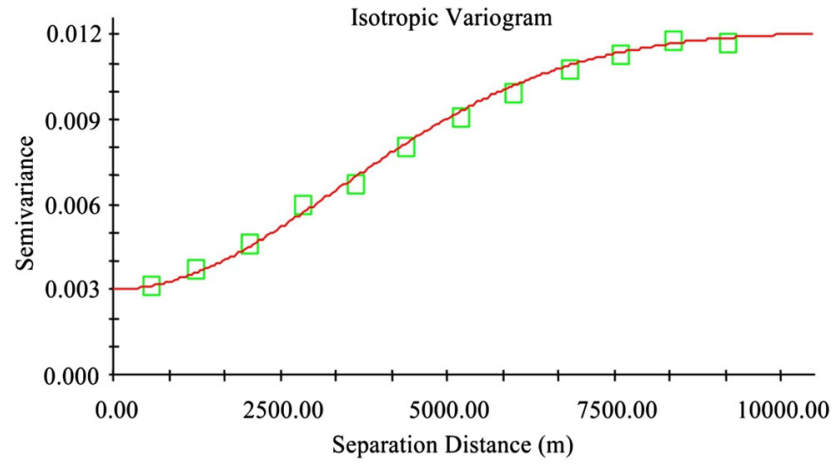

Fig. 2 Experimental semivariogram of groundwater EC and its fitted model

showed data were normalized because the amount of skewness was smaller than 0.5. The Kolmogorov-Smirnov test also demonstrated transformed data had normal distribution. Also, an analysis trend was applied, which determined there is no global trend for EC data.

Ordinary kriging technique for groundwater EC data performed. As seen in the variogram results (Table 2; Fig. 2) the most appropriate model fitted to groundwater EC is Gaussian. This model fitted to empirical semivariogram of groundwater EC include active lag distance 10,000, lag class distance interval (uniform interval) 800 , offset tolerance degree $22.5^{\circ}$, neighbors to include 20 , include at least 15 and sector type perpendicular tow line i.e. add symbol. High $\mathrm{R}^{2}$ and low RSS of this fitted model on empirical semivariogram implied that $\mathrm{OK}$ is the most appropriate model among others. The ratio of nugget effect to sill is smaller than 0.25 for variable; therefore Gaussian fitted model has strong spatial steal structure (Shi et al. 2007).

Performed RBF model for groundwater EC data had characteristics include kernel function spline with tension, parameter 0.09 , neighbors to include 16 , include at least 12 and sector type circular. IDW method performed on EC data with power values $1-5$. Neighbors are 14 with at least
Table 3 Evaluation results of prediction different methods

\begin{tabular}{lllll}
\hline Model & Power & $\mathrm{R}$ & RMSE & MAE \\
\hline Kriging & - & 0.87 & 0.123 & 0.090 \\
RBF & - & 0.82 & 0.125 & 0.091 \\
IDW & 1 & 0.82 & 0.126 & 0.093 \\
& 2 & 0.80 & 0.128 & 0.092 \\
& 3 & 0.78 & 0.135 & 0.094 \\
& 4 & 0.77 & 0.141 & 0.096 \\
& 5 & 0.75 & 0.145 & 0.098 \\
LPI & 4 & 0.71 & 0.128 & 0.094 \\
GPI & 6 & 0.69 & 0.131 & 0.096 \\
\hline
\end{tabular}

10 and sector type circular. In this method, the best and the most accurate result derived from power value 1 than the others. Characteristics of LPI technique used in this research were include optimize weight distance with weight $16,724.409$, neighbors are 341 with at least 10 and sector type multiple. This method had better result with power value equal to 4 for prediction of EC data (Table 3). While, the best export for GPI predictor model resulted when power value equal to 6 was applied (Table 3).

\section{Comparison of different interpolation techniques}

In this study, ordinary kriging, IDW, RBF, LPI and GPI were used to estimate groundwater electrical conductivity. After evaluating different models, it was demonstrated that the Gaussian model was the best suited for the variable and therefore, it was selected as the best fitted model on the data. Theory and empirical semivariogram were prepared for the $\mathrm{EC}$ in $\mathrm{GS}^{+}$media as shown in Fig. 2.

The summary statistics for geostatistic method showed that kriging with Gaussian model provides much better estimation results for EC than other methods (Table 3), this result was agree with findings of Babakhani et al. (2016). Kriging is a widely used method of geostatistical 
interpolation that assumes that no regional trend exists in the data. Comparison between the different methods was carried out by MAE, R and RMSE statistical parameters. RBF method has better result than IDW to simulate groundwater EC variable. IDW with power value equal 1 has the exact result than LPI and GPI.

Results of current study showed strong spatial structure of the variable data but the most appropriate results based on the statistical comparisons showed high capability of kriging technique because of statistical characteristics ordinary kriging technique such as correlation coefficient, root mean square error and mean absolutely error were better than other predictor methods (Table 3). Generally, our results were similar to Ahmed (2002), Barca and Passarella (2008), Mehrjardi et al. (2008), Nas (2009), Zehtabian et al. (2013) and Baram et al. (2014) results.

The validation and the sufficiency of the developed model variogram can be tested via a technique called cross validation. Cross validation estimation is obtained by leaving one sample out and using the remaining data. This test allows assessing the goodness of fitting of the variogram model, the appropriateness of neighborhood and type of kriging used. The interpolation values are compared to the real values and then the least square error models are selected for regional estimation (Leuangthong et al. 2004). Cross validation result of predicted and measured EC data in ordinary kriging method is presented in Fig. 3 and this graph show well evaluation of estimation by using this method.

Spatial variation maps of EC estimation by different interpolation methods are shown in Fig. 4. Electrical conductivity is higher in the north of studying area, Caspian Sea coastal land and lowlands than the other studied area. High EC in groundwater of coastal land is due to sea water seepage effect (Sainato et al. 2003) and in lowland could be

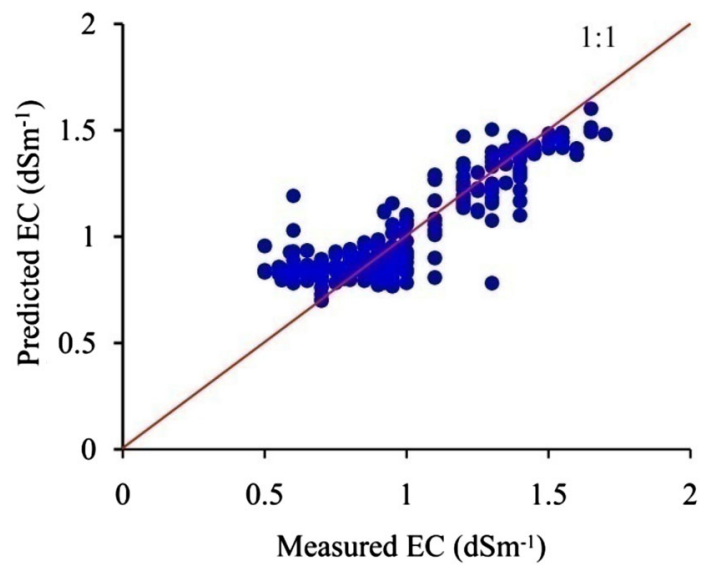

Fig. 3 The scatter plot of the measured versus predicted EC using the ordinary kriging method emergent of accumulation surface string aqueous from adjustment areas and irregular use of chemical fertilizers (Raju et al. 2015). Therefore, we proposed to set effective operations and to prevent increasing of groundwater EC in lowlands and coastal land in these research areas. If effective steps did not apply to control increasing of EC, these lands would be degraded and agriculture operations will not be economic in the future.

Improper and excessive use of irrigation water is one of the major factors aggravating the groundwater salinity. Chaudhuri and Ale (2014) reported that irrigation return flow is a major mechanism of solute enrichment of groundwater systems in agricultural regions in the Ogallala aquifer and that evaporative enrichment of salts in the upper part of soil profile and subsequent leaching of salts with irrigation water is a major cause of salt enrichment of shallow groundwater systems in Ogallala aquifer in the United States. Moreover, chemical species causing elevated EC and their potential sources should be identified to mitigate their further damage on groundwater and soils. Irrigation return flow had a diluting effect on groundwater $\mathrm{EC}$, as EC generally decreased following irrigation seasons in lowlands that these results are in line with findings of Liu et al. (2013) and Chaudhuri and Ale (2014). The US Salinity Laboratory classified groundwater by EC as $<0.25 \mathrm{dSm}^{-1}$ excellent, from 0.250 to $0.750 \mathrm{dSm}^{-1}$ good, from 0.75 to $2.25 \mathrm{dSm}^{-1}$ fair, and $>2.25 \mathrm{dSm}^{-1}$ poor (Kottureshwara et al. 2014). Our results exhibited that majority of study area had a groundwater with a good EC category, except some localities in the north of the study area. Interactions of irrigation water with natural processes should be recognized in groundwater salt enrichments. Under irrigated intensive agricultural production, considerable amount of salts may move beyond the root zone, degrading below groundwater. Plants uptake nearly pure water and leave salts behind (Chaudhuri and Ale 2014). The salts then are transported to groundwater by percolating water. During transportation, the salt rich percolating water interacts with soil and rock constituents and releases chemical species, further rising the salt concentration of groundwater (Kurunc et al. 2016).

\section{Conclusion}

Electrical conductivity is a parameter related to total dissolved solids (TDS). EC is actually a measure of solution in terms of its capacity to transmit current. The importance of EC and TDS lies in their effect on the corrosion of a water sample and in their effect on the solubility of slightly soluble compounds such as $\mathrm{CaCO}_{3}$. In general, as TDS and EC increase, the corrosion of the water increases. Therefore, study of spatial variation of 

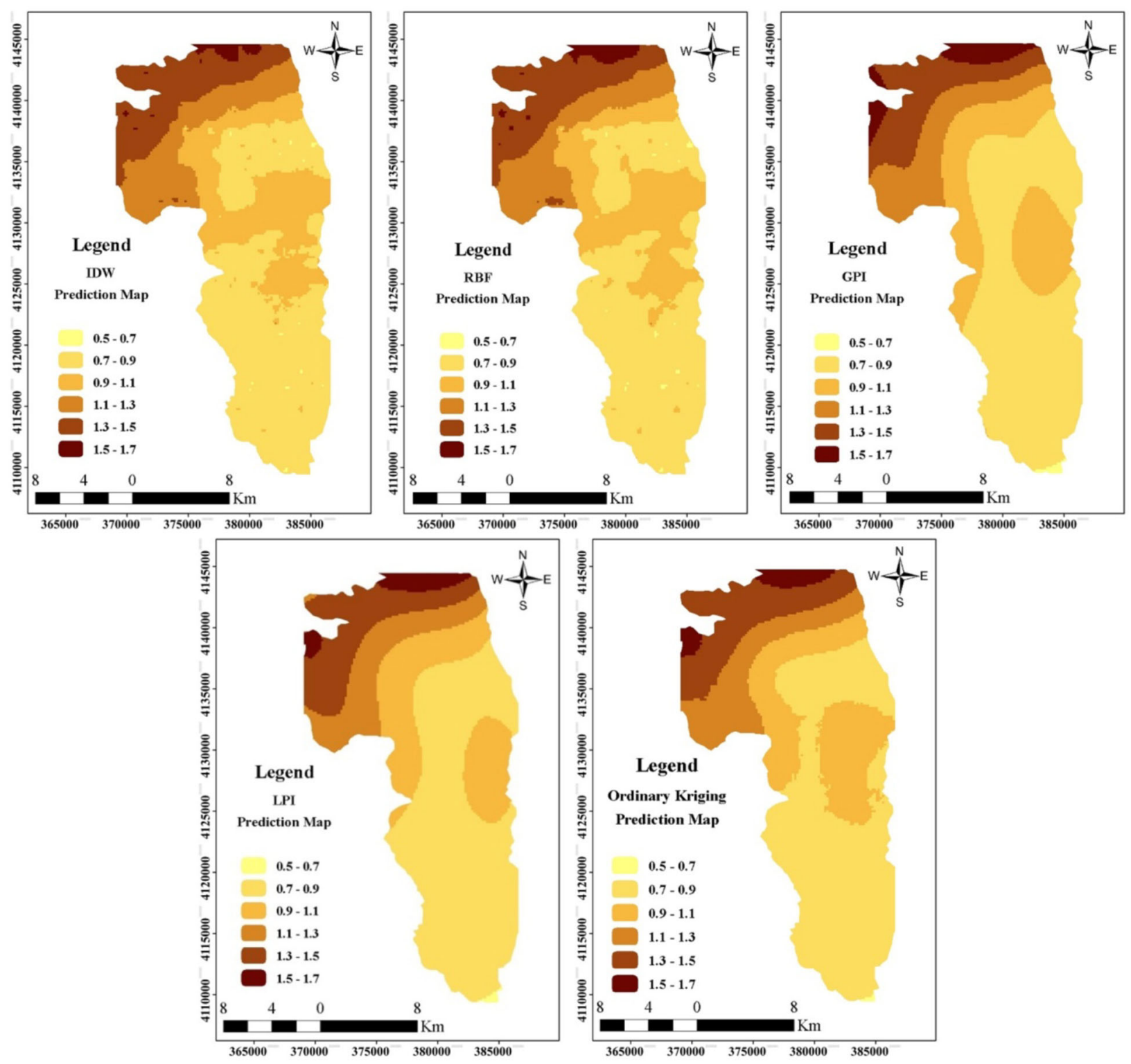

Fig. 4 Spatial distribution map of groundwater EC $\left(\mathrm{dSm}^{-1}\right)$ by different methods

groundwater EC is necessary for optimized management of groundwater resources. According to evaluation criteria, the accuracy of geostatistical methods in the estimation of groundwater EC is assessed as very good. The results showed that ordinary kriging can be applied as an appropriate tool to estimate the EC of groundwater in areas with data restriction. In this study, interpolation methods especially OK showed amount of groundwater EC was high in coastal land and lowlands than the other regions, therefore effective actions should carry out to prevent EC increasing. Generally, results of this research indicated that geostatistics models are suitable for estimation of groundwater quality.

Identification of spatial and temporal pattern of groundwater salt concentration and groundwater salinity is an important step in setting appropriate alternative management practices to protect land and soils against degradation. The data obtained in this study may help mitigate soil and groundwater degradation by climate change and human influence. Exceptional attention should be taken at locations with high groundwater EC contents. Results may have important implications for similar climate, topography, and soil conditions in other countries. It is important to define effect of irrigation and agricultural return flow in combination with chemical fertilizers on the quality and quantity of groundwater in the study area. In addition, impact of seawater intrusion from Caspian Sea via bed of Anzali Lagoon should be monitored frequently to avoid soil and groundwater degradation. Water quality of study area rivers should be monitored in regard with climate 
change to avoid irreversible impact of irrigation on soils and groundwater as already observed in many locations of Iran.

Degraded groundwater quality by increased salinization and salt ions of fertilizers was apparent from our results. Combination of natural and anthropogenic processes caused salinization in shallow groundwater in the study area. In some instances, natural processes were triggered by anthropogenic sources such as fertilizers, irrigation, and domestic waste disposals. Our results showed that elevated fertilizer salt ions concentrations and high groundwater salinity are growing concern in the study region. In addition to aquifer quality, shallow groundwater contamination in the study region should be considered in developing and implementing strategies for rural developments.

Acknowledgments This research was supported by University of Guilan, Iran. The authors thank for laboratory assistance of soil science department technicians in University of Guilan. The authors are grateful to anonymous reviewers who considerably improved the quality of the manuscript.

\section{References}

Ahmed S (2002) Groundwater monitoring network design: application of geostatistics with a few Case studies from a granitic aquifer in a semiarid region. In: Sherif MM, Singh VP, AlRashed M (eds) Groundwater hydrology, vol 2. Balkema, Tokyo, pp 37-57

Babakhani M, Zehtabian GH, Keshtkar AR, Khosravi H (2016) Trend of groundwater quality changes, using geo statistics (case study: Ravar Plain). Pollution 2(2):115-129. doi:10.7508/pj.2016.02. 002

Baram S, Kurtzman D, Ronen Z, Peeters A, Dahan O (2014) Assessing the impact of dairy waste lagoons on groundwater quality using a spatial analysis of vadose zone and groundwater information in a coastal phreatic aquifer. J Environ Manage 132:135-144. doi:10.1016/j.jenvman.2013.11.008

Barca E, Passarella G (2008) Spatial evaluation of the risk of groundwater quality degradation. A comparison between disjunctive kriging and geostatistical simulation. Environ Monit Assess 137(1-3):261-273. doi:10.1007/s10661-007-9758-3

Bhunia GS, Shit PK, Maiti R (2016) Comparison of GIS-based interpolation methods for spatial distribution of soil organic carbon (SOC). J Saudi Soc Agric Sci. doi:10.1016/j.jssas.2016. 02.001 (in press)

Bodrud-Doza M, Towfiqul Islam ARM, Ahmed F, Das S, Saha N, Safiur Rahman M (2016) Characterization of groundwater quality using water evaluation indices, multivariate statistics and geostatistics in central Bangladesh. Water Sci 30(1):19-40. doi:10.1016/j.wsj.2016.05.001

Chaudhuri S, Ale S (2014) Long term (1960-2010) trends in groundwater contamination and salinization in the Ogallala aquifer in Texas. J Hydrol 513:376-390. doi:10.1016/j.jhydrol. 2014.03.033

Dayani M, Mohammadi J (2010) Geostatistical assessment of Pb, Zn and $\mathrm{Cd}$ contamination in near-surface soils of the urban-mining transitional region of Isfahan, Iran. Pedosphere 20(5):568-577. doi:10.1016/S1002-0160(10)60046-X
Dhanasekarapandian M, Chandran S, Saranya Devi D, Kumar V (2016) Spatial and temporal variation of groundwater quality and its suitability for irrigation and drinking purpose using GIS and WQI in an urban fringe. J Afr Earth Sci. doi:10.1016/j.jafrearsci. 2016.08.015 (in press)

Ducci D, Condesso de Melo MT, Preziosi E, Sellerino M, Parrone D, Ribeiro L (2016) Combining natural background levels (NBLs) assessment with indicator kriging analysis to improve groundwater quality data interpretation and management. Sci Total Environ 569-570:569-584. doi:10.1016/j.scitotenv.2016.06.184

Han J, Huang Y, Li Z, Zhao C, Cheng G, Huang P (2016) Groundwater level prediction using a SOM-aided stepwise cluster inference model. J Environ Manage 182:308-321. doi:10.1016/j.jenvman.2016.07.069

Hani A, Abari SAH (2011) Determination of Cd, Zn, K, pH, TNV, organic material and electrical conductivity (EC) distribution in agricultural soils using geostatistics and GIS (case study: South Western of Natanz-Iran). World Acad Sci Eng Technol 5(12):22-25. https://docs.google.com/viewerng/viewer?url=http: //waset.org/publications/264/pdf

Kottureshwara NM, Manjappa S, Suresh T, Jayashree M (2014) Status of groundwater quality of Kudligi Taluk area in Bellary district, Karnataka, India. Int J Pharm Life Sci 5:3467-3473. http://www.ijplsjournal.com/issues\%20PDF\%20files/2014/april2014/8.pdf

Kumar A, Maroju S, Bhat A (2007) Application of ArcGIS geostatistical analyst for interpolating environmental data from observations. Environ Progress J 26(3):220-225. doi:10.1002/ep. 10223

Kurunc A, Ersahin S, Sonmez NK, Kaman H, Uz I, Uz BY, Aslan GE (2016) Seasonal changes of spatial variation of some groundwater quality variables in a large irrigated coastal Mediterranean region of Turkey. Sci Total Environ 554-555:53-63. doi:10. 1016/j.scitotenv.2016.02.158

Leuangthong O, McLennan JA, Deutsch CV (2004) Minimum acceptance criteria for geostatistical realizations. Nat Resour Res 13:131-141. doi:10.1023/B:NARR.0000046916.91703.bb

Lin GF, Chen LH (2004) A spatial interpolation method based on radial basis function networks incorporating a semivariogram model. J Hydrol 288(3-4):288-298. doi:10.1016/j.jhydrol.2003. 10.008

Liu XH, Simunek J, Li L, He JQ (2013) Identification of sulfate sources in groundwater using isotope analysis and modeling of flood irrigation with waters of different quality in the Jinghuiqu district of China. Environ Earth Sci 69:1589-1600. doi:10.1007/ s12665-012-1993-4

Mehrjardi TR, Jahromi MZ, Mahmodi S, Heidari A (2008) Spatial distribution of groundwater quality with geostatistics (case study: Yazd-Ardakan Plain). World Appl Sci J 4(1):9-17. http://www.idosi.org/wasj/wasj4(1)/2.pdf

Nas B (2009) Geostatistical approach to assessment of spatial distribution of groundwater quality. Polish J Environ Stud 18(6):1073-1082. http://www.pjoes.com/pdf/18.6/1073-1082.pdf

Nazarizadeh F, Ershadian B, Zandvakili K, Noori M (2005) Investigation of spatial variation of groundwater quality in Balarood plain of Khoozestan province, Iran. In: 1st regional conference, water resources revenue of Karoon and Zayandehrood watersheds, pp 1236-1240 (in Persian). http://www. civilica.com/Paper-COWR01-COWR01_193.html

Nourani V, Alami MT, Vousoughi FD (2015) Wavelet-entropy data preprocessing approach for ANN-based groundwater level modeling. J Hydrol 524:255-269. doi:10.1016/j.jhydrol.2015. 02.048

Raju NJ, Patel P, Gurung D, Ram P, Gossel W, Wycisk P (2015) Geochemical assessment of groundwater quality in the Dun valley of central Nepal using chemometric method and 
geochemical modeling. Groundw Sustain Dev 1:135-145. doi:10.1016/j.gsd.2016.02.002

Robinson TP, Metternicht GM (2006) Testing the performance of spatial interpolation techniques for mapping soil properties. Comput Electeron Agric 50:97-108. doi:10.1016/j.compag. 2005.07.003

Safari M (2002) Determination filtration network of Groundwater using geostatistic method. M.Sc Thesis. Tarbiyat Modares University Agricultural Faculty (in Persian)

Sainato C, Galindo G, Pomposiello C, Malleville H, Abelleyra D, Losinno B (2003) Electrical conductivity and depth of groundwater at the Pergamino zone (Buenos Aires Province, Argentina) through vertical electrical soundings and geostatistical analysis. J South Am Earth Sci 16:177-186. doi:10.1016/S08959811(03)00027-0

Shi J, Wang H, Xu J, Wu J, Liu X, Zhu H, Yu C (2007) Spatial distribution of heavy metals in soils: a case study of Changxing, China. Environ Geol 52:1-10. doi:10.1007/s00254-006-0443-6
Shrestha S, Semkuyu DJ, Pandey VP (2016) Assessment of groundwater vulnerability and risk to pollution in Kathmandu Valley, Nepal. Sci Total Environ 556:23-35. doi:10.1016/j.scitotenv. 2016.03.021

Wang YQ, Shao MA (2013) Spatial variability of soil physical properties in a region of the Loess Plateau of PR China subject to wind and water erosion. Land Degrad Dev 24(3):296-304. doi:10.1002/ldr.1128

Webster R, Oliver MA (2008) Geostatistics for environmental scientists, 2nd edn. Wiley, Brisbane. doi:10.1002/ 9780470517277

Zehtabian GR, Asgari HM, Tahmouresc M (2013) Assessment of spatial structure of groundwater quality variables based on the geostatistical simulation. Desert 17:215-224. https://jdesert.ut. ac.ir/article_35181_0be8db4dfaccaf59b7ae82dad1540073.pdf 